\title{
GAMBARAN LINGKUNGAN KERJA SOSIAL, PENGHARGAAN FINANSIAL DAN RETENSI KARYAWAN PADA PT. BAETT MAL ABADI DI CILEGON
}

\author{
Rizka Mayasari \\ Universitas Pendidikan Indonesia \\ rizka.mayasari95@student.upi.edu \\ Syamsul Hadi Senen \\ Universitas Pendidikan Indonesia \\ syamsulhadisenen@upi.edu \\ Eded Tarmedi \\ Universitas Pendidikan Indonesia \\ ededtarmedi@upi.edu
}

\begin{abstract}
ABSTRAK
Tujuan - Tujuan penelitian ini adalah untuk melihat gambaran lingkungan kerja sosial, penghargaan finansial dan retensi karyawan

Desain/metodologi/pendekatan - Desain penelitian ini adalah cross sectional. Penelitian ini menggunakan pendekatan deskriptif dengan metode explanatory survei. Sebanyak 86 responden dipilih dengan menggunakan nonprobability sampling. Sebuah angket digunakan sebagai instrumen penelitian untuk mengumpulkan data dari responden. Teknik analisis yang digunakan adalah teknik deskriptif dengan menggunakan distribusi frekuensi

Temuan - Berdasarkan hasil penelitian menggunakan analisis deskriptif, didapatkan hasil bahwa, lingkungan kerja sosial berada dalam kategori baik dengan skor 79\%, penghargaan finansial berada dalam kategori sesuai dengan skor $78 \%$, dan retensi karyawan berada dalam kategori tinggi dengan skor $80 \%$.

Orisinalitas/nilai - Penelitian ini memberikan dasar untuk memahami isu-isu lingkungan kerja sosial, penghargaan finansial dan retensi karyawan. Perbedaan penelitian ini dengan penelitian sebelumnya adalah pada objek yaitu perusahaan manufaktur, penelitian ini fokus pada lingkungan kerja sosial dan penghargaan finansial
\end{abstract}

Kata kunci: lingkungan kerja sosial, penghargaan finansial, retensi karyawan

Tipe Artikel: Studi Kasus

\begin{abstract}
Purpose - The purpose of this study is to see the description of social work environment, financial reward and employee retention

Design/methodology/approachh - The design of this study was cross sectional. This research uses descriptive approach with explanatory survey method. A total of 86 respondents were selected using probability sampling. A questionnaire was used as a research instrument to collect data from respondents. Analytical technique used is descriptive technique by using frequency table

Findings - Based on the results of the research using descriptive analysis, the results obtained that the social work environment is in the good category with a score of respectively $79 \%$, financial reward is in the good category with a score of respectively $78 \%$, employee retention is in the high category with a score of respectively $80 \%$

Originality/value - This study provides a basis for understanding social work environment issues, financial reward, employee retention. The difference of this study with previous research is focused on the social work environment, financial rewards.
\end{abstract}

Keywords: social work environment, financial reward, employee retention

Article Type : Case Study 


\section{PENDAHULUAN}

Sumber daya manusia adalah faktor dinamis yang mampu menentukan maju atau mundurnya suatu organisasi (Senen, Sumiyati, \& Masharyono, 2016). Berhasil atau tidaknya perusahaan dalam pencapaian tujuan tidak terlepas dari peran karyawan, memiliki tenaga kerja yang berkualitas adalah faktor pembeda utama bagi sebagian besar perusahaan (Regina, 2015). Memelihara dan menjaga karyawan yang berkinerja baik untuk tetap dalam perusahaan menjadi prioritas utama (Ahmad, Iqbal, \& Sheeraz, 2012).

Banyaknya karyawan yang meninggalkan perusahaan menjadi isu kontemporer dalam Manajemen Sumber Daya Manusia (MSDM) di seluruh dunia, karena retensi karyawan merupakan komponen krusial bagi efektivitas organisasi (Agyeman \& Ponniah, 2014). Organisasi menjadi lebih efektif jika memelihara tingginya retensi karyawan (Terera, 2014). Salah satu sumber daya yang merupakan aset terpenting organisasi adalah sumber daya manusia karena sumber daya manusia berperan dalam mencapai tujuan organisasi (Senen et al., 2016) Retensi karyawan diperkenalkan oleh Sheridan pada tahun 1992 (Agarwal, 2011; Khan et al., 2011; Rowley \& Jackson, 2012; Rasool et al., 2012; Ahmad et al,. 2015).

Kemajuan suatu perusahaan ditentukan oleh kualitas sumber daya manusia yang dimilikinya, sehingga sangatlah penting bagi suatu perusahaan untuk memperhatikan kualitas sumber daya manusia yang dalam hal ini adalah karyawannya (Senen \& Solihat, 2008). Perusahaan yang memiliki karyawan terampil adalah perusahaan yang akan memenangkan persaingan (Masharyono \& Senen, 2015). Organisasi membutuhkan ide dan pendapat dari karyawan mengenai hal yang menjadi perhatian di tempat kerja, karena karyawan melihat banyak hal sepanjang waktu ketika melakukan pekerjaan (Rahmawati, Sumiyati, \& Masharyono, 2016).

Permasalahan tingkat retensi karyawan terjadi pada beberapa industri salah satunya adalah industri manufaktur. Setiap perusahaan manufaktur memiliki tingkat retensi yang berbeda, hal ini disebabkan karena perbedaan penerapan jaminan kesejahteraan, standar gaji, dan kepuasaan karyawan (Umamaheswari \& Krishnan, 2015). Retensi karyawan relatif rendah ditandai dengan meningkatnya turnover karyawan. Tingkat turnover adalah salah satu kriteria untuk mengukur stabilitas yang terjadi di industri dan dapat mencerminkan tinggi atau rendahnya retensi karyawan di perusahaan (Allen, 2008).

Hay Group menjelaskan bahwa tingkat turnover karyawan di Asia Pasifik akan mengalami eskalasi yaitu rata-rata $24 \%$ selama 2013-2018 (Kanwal \& Majid, 2013; Omotayo \& Paul, 201; Salman \& Ahmad, 2014; Shukla, 2014; Imna \& Hassan, 2015). Perusahaan harus mempunyai strategi untuk meningkatkan retensi karyawan, karena jika retensi kayawan tinggi maka keberhasilan organisasi akan tercapai (Hee, Yean, \& Ling, 2011).

Dampak dari retensi karyawan yang rendah akan menyebabkan menurunnya kepuasan kerja karyawan (Fukofuka, 2014). Aspek psikologis yang muncul adalah menurunnya komitmen dari setiap individu untuk bekerja dengan sepenuh hati dalam memberikan kontribusi bagi tercapainya tujuan perusahaan (Kwenin, Muathe, \& Nzulwa, 2013). Konsekuensi dari penurunan kepuasan kerja dan komitmen adalah aspek non psikologis berupa perilaku yang diwujudkan oleh karyawan dengan adanya keinginan untuk keluar atau meninggalkan perusahaan atau intensi turnover (Agyeman \& Ponniah, 2014). Hilangnya karyawan akan berdampak negatif bagi perusahaan yaitu meningkatnya beban kerja bagi karyawan lain, naiknya beban operasi, kalah bersaing dari kompetitor dan menurunnya standar customer service (Thomas, 2015). Permasalahan retensi karyawan jika diabaikan akan menyebabkan menurunnya kinerja, produktivitas, dan efektivitas perusahaan (Mathis \& Jackson, 2010; Khan, Mahmood, Ayoub, \& Shabbir, 2011; Mohlala, Goldman, \& Goosen, 2012).

Berdasarkan beberapa penelitian faktor yang mempengaruhi retensi karyawan adalah lingkungan kerja, pelatihan, motivasi, pengembangan, rekrutmen, talent management, kepemimpinan, kepuasaan kerja, dan penghargaan (Sinha, 2012; Kwenin, 2013; Thakur, 2014; Msengeti \& Obwogi, 2015; dan Shakeel, 2015).

Solusi yang diambil untuk meningkatkan retensi karyawan yaitu dengan lingkungan kerja sosial dan penghargaan finansial. Solusi pertama yaitu lingkungan kerja sosial, penelitian yang dilakukan oleh Bt Fauzi, Ahmad, \& Gelaidan (2013) lingkungan kerja sosial berpengaruh terhadap retensi karyawan. Solusi kedua yaitu penghargaan finansial, dalam penelitian yang dilakukan oleh Inda (2016) menyatakan bahwa penghargaan finansial memiliki pengaruh positif dan signifikan terhadap retensi karyawan, sedangkan penelitian yang dilakukan oleh Msengeti \& Obwogi (2015) penghargaan finansial memiliki pengaruh yang lemah dalam meningkatkan retensi karyawan.

Tujuan penelitian ini adalah: 1) memperoleh temuan mengenai gambaran lingkungan kerja sosial, 2) memperoleh temuan mengenai gambaran penghargaan finansial, 3) memperoleh temuan mengenai gambaran retensi karyawan. 


\section{KAJIAN PUSTAKA}

Mengidentifikasi, mengakui, dan menjaga karyawan merupakan hal penting bagi organisasi. Manajemen sumber daya manusia harus menemukan cara untuk memastikan bahwa karyawan bertahan dalam perusahaan yang disebut sebagai retensi karyawan (Decenzo et al., 2013:123). Ivanovic \& Collin (2006:227) mendefinisikan retensi karyawan sebagai proses menjaga karyawan untuk tidak bekerja pada perusahaan lain agar mengurangi biaya perekrutan. Salah satu sikap positif dari karyawan adalah bertahan dalam perusahaan (Torrington et al., 2014:521). Retensi karyawan adalah masalah penting yang dihadapi para pemimpin perusahaan dikarenakan kekurangan tenaga kerja terampil, pertumbuhan ekonomi dan perputaran karyawan (Nkomo \& Thwala, 2016:305). Upaya sistematis dilakukan oleh perusahaan agar menciptakan dan menumbuhkan lingkungan yang mendorong karyawan untuk tetap bekerja dengan memiliki kebijakan yang memenuhi kebutuhan beragam (Satpal \& Dhillon, 2016:164).

Mendapatkan tenaga kerja yang kompeten dan berkualitas merupakan langkah pertama dalam mengelola sumber daya manusia, selanjutnya perusahaan harus melatih dan mengembangkan serta menjaga karyawannya (Robbins \& Coulter, 2016:306). Retensi karyawan berkaitan dengan menjaga atau mendorong karyawan untuk tetap dalam suatu organisasi dalam kurun waktu maksimal (Kossivi et al., 2016:262). Mathis \& Jackson (2010) menjelaskan bahwa retensi merupakan upaya untuk mempertahankan karyawan agar tetap berada dalam organisasi guna mencapai tujuan bersama. Retensi juga merupakan mengeliminasi karyawan yang berkinerja rendah untuk meningkatkan ruang lapang dan sumber daya lebih bagi karyawan yang berkinerja baik. Kebijakan retensi berfokus pada menghilangkan yang tidak baik bagi perusahaan dan mempertahankan karyawan yang terbaik (Armstrong \& Taylor, 2014:211).

Retensi karyawan didefinisikan sebagai teknik yang diadopsi oleh perusahaan untuk mempertahankan tenaga kerja yang efektif dan pada saat yang sama memenuhi persyaratan operasional (Mehta et al., 2014:154). Secara luas retensi karyawan yaitu seberapa banyak karyawan sebuah perusahaan tetap berada di perusahaan tersebut dalam suatu jangka waktu tertentu (Akila, 2012:18), serta proses fisik menjaga sumber daya manusia dalam suatu organisasi karena merupakan salah satu dasar utama yang diperlukan bagi keberhasilan organisasi (Bhalla et al., 2016:118). Dimensi retensi karyawan yaitu, 1)
Niat untuk bertahan, 2) Peluang Karir, dan 3) Komitmen (Kyndt et al., 2009:202).

Berdasarkan veldman's employee commitment model (Agyeman \& Ponniah, 2014:18) terdapat lima dimensi dalam retensi karyawan, yaitu: 1) Employer of choice, 2) Organizational climate \& culture, 3) Job satisfaction, 4) Employee well-being. Gupta (2010) dalam penelitiannya menambahkan tiga dimensi retensi karyawan, yaitu: 1) Intrinsic motivation, 2) Hygiene, 3) Life interest and work compatibility, 4) Involvement. Das \& Baruah (2013:9) dalam penelitiannya menemukan retensi karyawan dibentuk dengan tiga unsur, yaitu 1) Social, yaitu hubungan internal maupun eksternal antara karyawan. 2) Mental, yaitu berupa karakteristik pekerjaan berupa tugas kerja fleksibel yang membantu dalam mempertahankan sumber daya. 3) Physical, yaitu kondisi kerja dan upah.

Lingkungan kerja dan kemampuan kerja dijadikan sebagai cara untuk meningkatkan kinerja karyawan (Widyanata \& Senen, 2016). Lingkungan kerja sosial merupakan kelompok lingkungan kerja yang tidak dapat diabaikan dan salah satu aspek penting bagi organisasi untuk mencapai target yang sudah ditetapkan. Perusahaan hendaknya mencerminkan kondisi yang mendukung kerjasama antara tingkat atasan, bawahan maupun yang memiliki jabatan yang sama di perusahaan. Keadaan yang terjadi dan berkaitan dengan hubungan kerja, baik hubungan dengan atasan, hubungan dengan sesama rekan kerja maupun pelayanan kepada masyarakat disebut sebagai lingkungan kerja sosial (Sedamaryanti, 2011).

Lingkungan kerja sosial adalah aspek psikologis kerja dan peraturan kerja yang dapat mempengaruhi kepuasan kerja dan pencapaian produktivitas (Schultz \& Schultz, 2010:150), salah satu ukuran keberhasilan kinerja individu, tim atau organisasi yang berada pada produktivitas (Masharyono, Sumiyati, \& Toyib, 2016). Sesuatu yang berhubungan dengan segi psikis dari lingkungan kerja disebut sebagai lingkungan kerja sosial (Mondy \& Martocchio, 2016:361). Lingkungan kerja sosial atau lingkungan kerja sosial hanya dapat dirasakan dan tidak dapat ditangkap dengan panca indera (Sutermeister, 1976:56). Lingkungan kerja sosial yang baik sangat dibutuhkan oleh karyawan di semua tingkat manajemen untuk meningkatkan produktivitas karyawan (Sumiyati, Masharyono, Pratama, \& Purnama, 2016).

Dimensi lingkungan kerja sosial yaitu, hubungan karyawan dngan atasan dan hubungan karyawan dengan bawahan (Sedamaryanti, 2011:46). Breinegaard et al. (2017) menyatakan bahwa lingkungan kerja sosial terbentuk karena 
tiga unsur, yaitu: 1) Social capital, 2) Organizational justice, dan 3) Quality of management.

Dimensi lingkungan kerja sosial menurut Schultz \& Schultz (2010:105), 1) Kondisi temporal, berhubungan dengan peraturan lama jam kerja, waktu istirahat, dan perubahan pergantian jadwal agar karyawan merasa nyaman, dan 2) Kondisi psikologis, berhubungan dengan lokasi ruang kerja dan pengawasan lingkungan kerja yang dapat mempengaruhi produktivitas. Kebosanan, pekerjaan yang monoton, dan keletihan penting diperhatikan oleh perusahaan.

Sutermeister (1976:57) menjelaskan beberapa dimensi yang ada dalam lingkungan kerja sosial, yaitu 1) Leadership (Kepemimpinan), pemimpin adalah mereka yang menggunakan wewenang formal untuk mengorganisasikan, mengarahkan, mengontrol para bawahan yang bertanggung jawab, supaya semua bagian pekerjaan dikoordinasi demi mencapai tujuan perusahaan, 2) Union (Serikat Kerja), serikat kerja merupakan sistem sosial terbuka yang mengejar tujuan seringkali di pengaruhi oleh lingkungan luar. Serikat pekerja merupakan wadah bagi karyawan sebagai wahana untuk berpartisipasi dalam perusahaan. 3) Formal Organization (Organisasi Formal), organisasi formal adalah kumpulan dari dua orang atau lebih yang mengingatkan diri dengan suatu tujuan bersama secara sadar serta dengan hubungan kerja yang rasional. Organisasi formal harus memiliki tujuan dan sasaran, 4) Informal Organization (Organisasi Informal), organisasi informal adalah hasil keseluruhan hubungan pribadi yang terjalin antara individu maupun kelompok-kelompok manusia.

Penghargaan finansial terdiri dari semua hasil yang memiliki nilai dan karakteristik moneter (Nankervis et al., 2016:79). Insentif gaji merupakan bagian penghargaan finansial digunakan untuk memotivasi karyawan agar memiliki peningkatan kinerja dalam bekerja (Gomez-Mejia \& Balkin, 2012:100). Karyawan diberikan penghargaan finansial karena mencapai atau melebihi standar produksi perusahaan (Dessler, 2014:462). Penghargaan finansial dapat berupa langsung dan tidak langsung (Armstrong \& Taylor, 2014:163; Dessler, 2014:275; Mondy \& Martocchio, 2016:280).

Penghargaan finansial diberikan kepada karyawan tergantung pada kinerja, kontribusi, kompetensi atau keterampilan karyawan yang terdiri dari penghargaan langsung dan penghargaan tidak langsung (Wilkinson et al. 2017:162). Penghargaan langsung yaitu gaji dan insentif sedangkan penghargaan tidak langsung yaitu tunjangan-tunjangan seperti pensiun, asuransi kesehatan, cuti absen dan liburan.
Penghargaan finansial adalah penghargaan berupa uang atau materi yang menjadi motivator apabila terdapat hubungan antara kinerja dan peningkatan kompensasi (Gibson et al., 2012:177). Dimensi penghargaan finansial yang digunakan mengacu pada teori Wilkinson et al. (2017:162) yaitu, penghargaan finansial langsung berupa gaji dan bonus, serta penghargaan finansial tidak langsung berupa tunjangan.

Dessler (2014:275) membagi komponen penghargaan finansial menjadi dua yaitu, 1) Direct financial payments (wages, salaries, incentives, commissions, and bonuses), 2) Indirect financial payments (financial benefits seperti asuransi dan liburan). Shields (2014:31) mengatakan bahwa terdapat tiga dimensi penghargaan finansial, yaitu 1) Fixed or base pay, 2) Direct benefits, dan 3) Performance-related pay. Teori yang dikemukakan Decenzo et al. (2013:277) dan Torrington et al. (2014:207) penghargaan finansial terbentuk oleh, 1) Performanced based, 2) Implied membership based, dan 3) Explicit membership based. Mondy \& Martocchio (2016:280) berpendapat bahwa terdapat dua elemen pembentuk penghargaan finansial yaitu, 1) Penghargaan langsung, dan 2) Penghargaan tidak langsung berupa legally required benefits dan discretionary benefits.

\section{METODE PENELITIAN}

Penelitian ini dilakukan untuk mengetahui gambaran lingkungan kerja sosial, penghargaan finansial, dan retensi karyawan. Variabel bebas yang terdapat pada penelitian ini yaitu lingkungan kerja sosial dengan dimensi hubungan karyawan dengan atasan dan hubungan karyawan dengan rekan kerja. Dan penghargaan finansial dengan dimensi gaji, insentif dan finansial tidak langsung. Sedangkan variabel terikat yaitu retensi karyawan dengan dimensi niat untuk bertahan, peluang karir, dan komitmen.

Objek/unit analisis pada penelitian ini adalah karyawan PT. Baett Mal Abadi Cilegon. Penelitian ini dilakukan pada kurun waktu kurang dari satu tahun, sehingga teknik pengumpulan data yang digunakan pada penelitian ini adalah cross-sectional method. Teknik yang digunakan dalam penelitian ini adalah teknik nonpropability sampling dengan pengambilan jumlah sampel sebanyak 86 karyawan. Teknik pengumpulan data yang digunakan adalah studi kepustakaan, studi lapangan dengan penyebaran angket secara langsung, dan studi literatur. Sedangkan teknik analisis data yang dilakukan adalah analisis deskriptif dengan menggunakan tabel frekuensi. 


\section{HASIL PENELITIAN DAN PEMBAHASAN}

\section{Gambaran Lingkungan Kerja Sosial}

Tabel 1

Rekapitulasi Variabel Lingkungan Kerja Sosial

\begin{tabular}{|c|c|c|c|c|}
\hline No. & Dimensi & $\begin{array}{l}\text { Total } \\
\text { Skor }\end{array}$ & $\begin{array}{l}\text { Skor } \\
\text { Ideal }\end{array}$ & $\%$ \\
\hline \multicolumn{5}{|c|}{ Lingkungan Sosial } \\
\hline 1. & Hubungan Karyawan dengan Atasan & 1680 & 2150 & $78 \%$ \\
\hline \multirow[t]{2}{*}{2.} & Hubungan Karyawan dengan Rekan Kerja & 2075 & 2580 & $80 \%$ \\
\hline & Total & 3755 & 4730 & $79 \%$ \\
\hline
\end{tabular}

Berdasarkan hasil penelitian dari angket yang disebar kepada 86 responden dapat diketahui bahwa lingkungan kerja sosial PT. Baett Mal Abadi Cilegon mencapai skor 3755 dari skor kriterium atau jumlah maksimal. Perolehan nilai responden teretak pada kategori baik yaitu interval 3216,4 sampai 3973,3, skor tertinggi berdasarkan hasil jawaban responden terdapat pada dimensi hubungan karyawan dengan rekan kerja dengan peroleh skor 2075 atau sebesar $80 \%$ dari skor ideal.

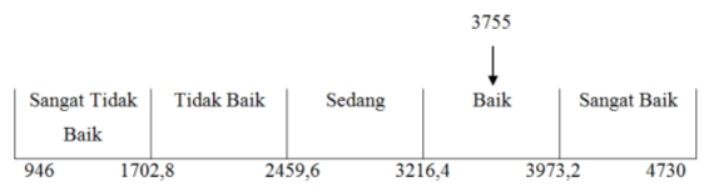

\section{Gambar 1 Hasil Kontinum Variabel Lingkungan} Kerja Sosial

Skor tertinggi berdasarkan hasil jawaban responden terdapat pada dimensi hubungan karyawan dengan rekan kerja dengan peroleh skor 2075 atau sebesar 80\% dari skor ideal yang memiliki makna bahwa persepsi hampir seluruh responden tentang hubungan karyawan dengan rekan kerja terjalin dengan sangat baik. Hubungan sosial sesama rekan kerja yang berlangsung dengan baik akan membantu karyawan mendapatkan rasa nyaman dalam bekerja sehingga dapat tercipta kinerja yang baik. Proses interaksi yang dilakukan dengan sesama rekan kerja berupa kontak sosial dan komunikasi berupa pembahasan mengenai masalah untuk mencari solusi sehingga meningkatkan kualitas kinerja karyawan. Hubungan yang harmonis dengan rekan kerja berupa interaksi yang efektif akan mampu memotivasi karyawan dalam bekerja untuk mendapatkan keberhasilan mencapai tujuan bersama.

Sementara skor terendah terdapat pada dimensi hubungan karyawan dengan atasan diperoleh skor 1680 atau sebesar $78 \%$ yang memiliki makna bahwa persepsi hampir seluruh responden tentang hubungan karyawan dengan atasan adalah sedang. Hubungan sosial atasan terhadap bawahan memberikan pengaruh bagi karyawan dalam melaksanakan aktivitasnya. Sikap yang bersahabat, saling menghormati dan menghargai perlu dalam hubungan antar karyawan dengan pimpinan untuk kerjasama dalam mencapai tujuan perusahaan. Sikap bersahabat yang diciptakan atasan akan menjadikan karyawan lebih betah untuk bekerja dan dapat menimbulkan semangat kerja bagi karyawan. Dalam hal ini menunjukkan bahwa hubungan atasan dan bawahan yang harmonis penting untuk diperhatikan.

Pemeliharaan hubungan sosial dalam rangka keseluruhan proses manajemen SDM berkisar pada pemikiran bahwa hubungan yang resasi dan harmonis antara atasan dengan karyawan yang terdapat dalam perusahaan perlu ditumbuhkan, dijaga dan dipelihara demi kepentingan bersama dalam perusahaan. Kekurangberhasilan memelihara hubungan yang serasi dan harmonis ini akan merugikan banyak pihak dan tidak terbatas hanya pihak manajemen, tetapi pada kepuasan kerja karyawan juga.

Konsep hubungan imbal balik atasanbawahan adalah sebuah teori yang mempelajari bentuk-bentuk hubungan yang bervariasi antara atasan dengan bawahan dan pertukaran perlakuan secara vertikal antara keduanya (Mondy \& Martocchio, 2016). Hubungan yang berbeda-beda antara atasan dan bawahan ini bisa dikategorikan ke dalam dua titik ekstrem hubungan, yaitu hubungan dengan kualitas tinggi dan hubungan dengan kualitas rendah. Hubungan dengan kualitas tinggi ditandai dengan kedekatan antara atasan dan bawahan, kedekatan antara atasan dan bawahan sehingga hubungan ini bisa dikategorikan sebagai hubungan in-group, sementara hubungan dengan kualitas rendah menandakan adanya jarak tertentu sehingga bisa dikategorikan sebagai out-group (Sedamaryanti, 2011).

Usaha menciptakan lingkungan kerja sosial adalah dengan human relations yang baik serta atasan juga dapat menyediakan pelayanan kepada karyawan sehingga karyawan merasa aman dan nyaman di dalam perusahaan karena kebutuhan psikologisnya dapat terpenuhi.

\section{Gambaran Lingkungan Kerja Sosial}

Tabel 2

Rekapitulasi Variabel Penghargaan Finansial

\begin{tabular}{lllll}
\hline No. & Dimensi & $\begin{array}{l}\text { Total } \\
\text { Skor }\end{array}$ & $\begin{array}{c}\text { Skor } \\
\text { Ideal }\end{array}$ & $\begin{array}{c}\text { \% } \\
\text { Penghargaan Finansial }\end{array}$ \\
\hline 1. Gaji & 1306 & 1720 & $76 \%$ \\
2. Insentif & 1038 & 1290 & $80 \%$ \\
3. & Keamanan & 1344 & 1720 & $78 \%$ \\
\hline \multicolumn{2}{c}{ Total } & $\mathbf{3 6 8 8}$ & $\mathbf{4 7 3 0}$ & $\mathbf{7 8 \%}$ \\
\hline
\end{tabular}


Berdasarkan hasil penelitian dari angket yang disebar kepada 86 responden dapat diketahui bahwa variabel penghargaan finansial PT. Baett Mal Abadi Cilegon mencapai 3688 dari skor kriterium atau jumlah maksimal perolehan nilai responden terletak pada kategori sesuai yaitu pada interval 3216,4 sampai 3973,2. Skor tertinggi berdasarkan hasil jawaban responden terdapat pada dimensi insentif dengan peroleh skor 1038 atau sebesar $80 \%$ dari skor ideal.

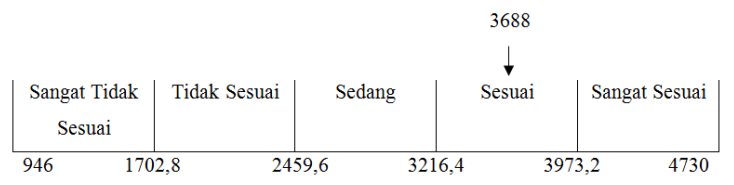

Gambar 2

Hasil Kontinum Variabel Penghargaan Finanasial

Skor tertinggi berdasarkan hasil jawaban responden terdapat pada dimensi insentif dengan memperoleh skor sebanyak 1038 atau 80\% dari skor ideal yang memiiki makna bahwa persepsi hampir seluruh responden menyatakan bahwa insentif karyawan sudah sesuai. Insentif merupakan balas jasa diluar gaji yang diberikan kepada karyawan berdasarkan hasil kerja dengan maksud agar karyawan mau bekerja dengan lebih baik dan agar mampu mencapai tingkat kinerja yang lebih tinggi, jadi seseorang mau bekerja dengan sungguh-sungguh jika didalam dirinya terdapat semangat kerja yang tinggi. Pemberian insentif dimaksudkan agar dapat memenuhi kebutuhan para karyawan dan keluarga mereka. Insentif merupakan tambahan balas jasa yang diberikan kepada karyawan yang memiliki prestasi diatas prestasi standar (Hasibuan, 2007:114). Insentif adalah alat yang menggunakan pendukung prinsip adil dalam pemberian kompensasi. Pemberian insentif dapat menimbulkan semangat kerja dari dalam diri seorang karyawan yang lebih besar dari sebelumnya untuk lebih berprestasi lagi bagi peningkatan kinerjanya.

Sementara skor terendah terdapat pada dimensi gaji sebanyak $76 \%$ dari skor ideal yang meiliki makna bahwa persepsi hampir seluruh responden menunjukkan bahwa gaji yang diberikan pada karyawan sudah sesuai. Dalam hal ini karyawan merasa gaji yang diberikan belum memenuhi kebutuhannya. Gaji adalah sejumlah uang yang diterima oleh tenaga-tenaga majerial dan tata usaha atas sumbangan jasanya, yang menerima uang dengan jumlah yang tetap berdasarkan tarif bulanan (Tulus, 2011:140). Besarnya gaji pokok ataupun tunjangan yang diberikan kepada karyawan, pada saat-saat tertentu akan dievaluasi (Moeheriono, 2012). Kemungkinan bahwa besarnya tunjangan ataupun fasilitas yang diberikan kepada karyawan, akan mengalami penurunan. Hal ini disebabkan karyawan yang bersangkutan mungkin sudah tidak menjabat pada posisi tersebut lagi, sehingga karyawan yang bersangkutan tidak berhak lagi untuk menerimanya. Dengan demikian, selain menerima gaji pokok yang besarnya telah ditentukan, pada umumnya setiap karyawan juga akan menerima berbagai macam tunjangan serta dikurangi dengan berbagai macam kewajiban yang harus dibayarkan kepada perusahaan.

Menurut Notoatmodjo (2010) faktor-faktor yang mempengaruhi penghargaan finansial adalah, 1) Produktivitas, perusahaan berkeinginan untuk memperoleh keuntungan berupa material, maupun non material maka perusahaan harus mempertimbangkan produktivitas. 2) Kemampuan untuk membayar, pemberian penghargaan finansial akan tergantung kepada kemampuan perusahaan itu untuk membayar (ability to pay), 3) Kesediaan untuk membayar, kesedian untuk membayar (willingness to pay) akan berpengaruh terhadap kebijaksanaan pemberian penghargaan finansial kepada karyawannya, 4) Permintaan tenaga kerja, banyak sedikitnya tenaga kerja di pasaran kerja akan mempegaruhi sistem pemberian penghargaan finansial, 5) Organisasi karyawan, organisasiorganisasi karyawan akan mempengaruhi kebijakan pemberian penghargaan finansial, 6) Berbagai Peraturan dan Perundang-undangan, sistem pemerintahan semakin baik, maka makin baik pula sistem perundang-undangan termasuk di bidang perburuhan (karyawan) atau ketenagakerjaan. karyawannya dalam kontribusinya terhadap keuntungan perusahaan.

\section{Gambaran Retensi Karyawan}

Tabel 1

Rekapitulasi Variabel Retensi Karyawan

\begin{tabular}{lcccc}
\hline No. & Dimensi & $\begin{array}{l}\text { Total } \\
\text { Skor }\end{array}$ & $\begin{array}{c}\text { Skor } \\
\text { Ideal }\end{array}$ & $\%$ \\
\hline Retensi Karyawan & & & \\
\hline 1. & Niat untuk Bertahan & 1059 & 1290 & $82 \%$ \\
2. Peluang Karir & 673 & 860 & $78 \%$ \\
3. Komitmen & 1366 & 1720 & $79 \%$ \\
\hline \multicolumn{2}{c}{ Total } & $\mathbf{3 0 9 8}$ & $\mathbf{3 8 7 0}$ & $\mathbf{8 0 \%}$ \\
\hline
\end{tabular}

Berdasarkan hasil penelitian dari angket yang disebat kepada 86 responden dapat diketahui bahwa retensi karyawan PT. Baett Mal Abadi mencapai 3098 dari skor kriterium atau jumlah maksimal perolehan nilai responden terletak pada kategori sedang pada interval 2631,6 sampai 3250,8 . Skor tertinggi terdapat pada dimensi niat untuk bertahan dengan skor 1059 atau sebesar $82 \%$. 


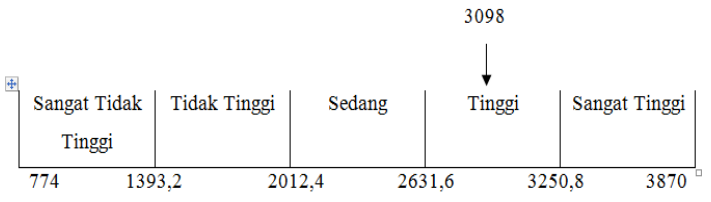

Gambar 3

Hasil Kontinum Variabel Retensi Karyawan

Dalam hal ini menunjukkan bahwa karyawan memiliki niat yang tinggi untuk tetap berada di dalam perusahaan. Niat karyawan untuk bertahan dalam sebuah organisasi merupakan kondisi dimana karyawan cenderung ingin tinggal bersama organisasi sampai keadaan dimana para karyawan terpaksa harus pergi atau meninggalkan organisasi dengan alasan tertentu. Niat untuk tetap tinggal di perusahaan merupakan proses psikologis (Dessler, 2014). Konsep intention to stay mengacu pada tingkat kemungkinan seorang karyawan yang berencana untuk tetap dengan organisasi. Perusahaan tidak dapat menganggap bahwa karyawan tidak akan pergi ketika mereka melihat kesempatan kerja yang lebih besar diluar organisasi. Komitmen yang tepat akan memberikan motivasi yang tinggi dan memberikan dampak yang positif terhadap kinerja suatu pekerjaan. Jika auditor merasa jiwanya terikat dengan nilai-nilai organisasional yang ada maka dia akan merasa senang dalam bekerja, sehingga kinerjanya dapat meningkat. Hal ini berarti bahwa semakin tinggi komitmen seorang auditor pemerintah terhadap organisasi, maka kinerja auditor pemerintah akan semakin baik (Wadhana, Tarmedi, \& Sumiyati, 2016).

Menurut Hasibuan (2007) upaya yang dapat dilakukan dalam meningkatkan retensi karyawan, yaitu 1) Komunikasi, 2) Pemberian insentif, 3) Kesejahteraan karyawan, 4) Keselamatan karyawan, dan 5) Hubungan industrial.

\section{KESIMPULAN DAN REKOMENDASI}

Berdasarkan hasil penelitian yang telah dilakukan menggunakan analisis deskriptif dapat diambil kesimpulan yaitu, hasil penelitian menyatakan bahwa Gambaran lingkungan sosial di PT. Baett Mal Abadi Cilegon berdasarkan persepsi hampir seluruh responden menyatakan bahwa lingkungan sosial PT. Baett Mal Abadi pada kategori baik, Gambaran penghargaan finansial di PT. Baett Mal Abadi Cilegon berdasarkan persepsi hampir seluruh responden menyatakan bahwa penghargaan finansial PT. Baett Mal Abadi sudah sesuai, Gambaran retensi karyawan di PT. Baett Mal Abadi Cilegon hampir seluruh responden menyatakan bahwa retensi karyawan PT. Baett Mal Abadi pada kategori tinggi.
Adanya penelitian ini diharapkan dapat membantu peneliti berikutnya dalam melakukan penelitian mengenai lingkungan kerja sosial dan penghargaan finansial serta retensi karyawan dengan menggunkan indikator yang berbeda dari sumber teori yang lebih beragam, dan terhadap objek yang berbeda, karena masih banyaknya keterbatasan dalam penelitian ini, khususnya yang berkaitan dengan metode penelitian dan teknik pengumpulan data.

\section{DAFTAR PUSTAKA}

Agarwal, R. N. (2011). Assertive Leadership and Employee Engagement and its Impact on Retention. International Journal in Multidisciplinary and Academic Research (SSIJMAR), 1(4), 1-20.

Agyeman, C. M., \& Ponniah, V. M. (2014). Employee Demographic Characteristics and Their Effects on Turnover and Retention in MSMEs. International Journal of Recent Advances in Organzitional Behaviour and Decision Sciences, 1(1), 12-29.

Ahmad, N., Iqbal, N., \& Sheeraz, M. (2012). The Effect of Internal Marketing on Employee retention in Pakistani Banks. International Journal of Academic Research in Business and Social Sciences, 2(8), 270-280. Retrieved from http://www.hrmars.com/admin/pics/1055.p df

Ahmad, N., Sulaman, M., \& Hussain, A. (2015). Human resource practices and employee retention, evidences from banking sector of Pakistan. Journal of Business and Management Research, 7, 186-188.

Akila, R. (2012). A Study on Employee Retention Among Executives at BGR Energy Systems LTD, Chennai. International Journal of Marketing, Financial Services \& Management Research, 1(9), 18-32.

Allen, D. G. (2008). Retaining Talent: A Guide to Analyzing and Managing Employee Turnover. SHRM Foundation. US: SHRM Foundation. Retrieved from http://www.shrm.org/about/foundation/rese arch/documents/retaining talent- final.pdf

Armstrong, M., \& Taylor, S. (2014a). Armstrong's Handbook of Human Resource Management Practice (13th ed.). London: KoganPage. http://doi.org/10.1177/03091325890130010 5

Armstrong, M., \& Taylor, S. (2014b). Handbook of Human Resource Management Practice 
(13th ed.). UK: Kogan Page. http://doi.org/10.1177/03091325890130010 5

Bhalla, R., Mittal, R., \& Wala, N. S. (2016). Workforce Retention: A Serious Issue Of Colleges and Universities in Punjab and Chandigarh. International Journal of Advanced Research, 4(1), 118-136.

Breinegaard, N., Jensen, J. H., \& Bonde, J. P. (2017). Organizational Change, Psychosocial Work Environment, and NonDisability Old-Age Retirement: a Prospective Study Among Senior Public Employees. Scandinavian Journal of Work, Environment \& Health, 40(2), 1-7. http://doi.org/10.5271/sjweh.3624

Bt Fauzi, N. F., Ahmad, F., \& Gelaidan, H. M. (2013). The Employee Retention Status in Paddy and Rice Industry in Malaysia. Middle-East Journal of Scientific Research, 18(5), 642-650. http://doi.org/10.5829/idosi.mejsr.2013.18.5 .11732

Das, B. L., \& Baruah, M. (2013). Employee Retention: A Review of Literature. IOSR Journal of Business and Management (IOSR-JBM), 14(2), 8-16.

Decenzo, D. A., Robbins, S. P., \& Verhurlst, S. L. (2013). Fundamentals of Human Resource Management (11th ed.). United States of America: Wiley.

Dessler, G. (2014). Pearson New International Edition Fundamentals of Human Resource Management (3th ed.). United States of America: http://doi.org/0470169680

Fukofuka, S. (2014). Factor that predict employee retention in profit and non profit organizations. Global Journal of Human Resource Management, 2(4), 1-8.

Gibson, J. L., Ivancevich, J. M., Donnelly, J. H., \& Konopaske, R. (2012). Organizations: Behavior, Structure, Processes (14th ed.). New York: McGraw-Hill.

Gupta, S. Sen. (2010). Employee Attrition and Retention: Exploring the Dimensions in the Urban Centric Bpo Industry. Jaypee Institute of Information Technology.

Hasibuan, M. (2007). Manajemen Sumber Daya Manusia (Cetakan 9). Jakarta: Bumi Aksara.

Hee, C. H. S., Yean, F., \& Ling, Y. (2011). Strategies for Reducing Employee Turnover and Increasing Retention Rates of Quantity Surveyors. Construction Management and Economics, 29(4), 1059-1072. http://doi.org/10.1080/01446193.2011.6375 69

Imna, M., \& Hassan, Z. (2015). Influence of Human Resource Management practices on Employee Retention in Maldives Retail Industry. International Journal of Accounting, Business and Management, $1(1), 1-28$

Inda, S. S. (2016). Review of Literature on Influence of Job Satisfaction, Employee Compensation, working environment on Employee Retentiom. IJARIIE, 2(1), 416421.

Ivanovic, \& Collin. (2006). Dictionary of Human Resources and Personnel Management (3th ed.). Italy: A \& C Balck.

Kanwal, A., \& Majid, M. (2013). Retention Management in Banking System an Evidance From Multan, Punjab Pakistan. Interdisciplinary Journal of Contemporary Research in Business, 5(1), 795-804.

Khan, A. A., Mahmood, B., Ayoub, M., \& Shabbir, H. (2011). An empirical study of retention issues in hotel industry: A case study of Serena Hotel, Faisalabad, Pakistan. European Journal of Economics, Finance and Administrative Sciences, 29(29), 7-18. Retrieved from http://www.academia.edu/download/30873 102/EJEFAS_29_01.pdf

Kossivi, B., Xu, M., \& Kalgora, B. (2016). Study on Determining Factors of Employee Retention. Open Journal of Social Sciences, 4, 261-268.

Kwenin, D. O. (2013). Relationship Between Work Environment, Career Development Opportunities and Employee Retention in Vidavone Ghana Limited. Global Journal of Human Resource Management, 1(4), 19.

Kwenin, D. O., Muathe, S., \& Nzulwa, R. (2013). The Influence of Employee Rewards, Human Resource Policies and Job Satisfaction on the Retention of Employees in Vodafone Ghana Limited. European Journal of Business and Management, 5(12), 2222-2839.

Kyndt, E., Dochy, F., Michielsen, M., \& Moeyaert, B. (2009). Employee retention: Organisational and Personal Perspectives. Vocations and Learning, 2(3), 195-215. 
http://doi.org/10.1007/s12186-009-9024-7

Masharyono, \& Senen, S. H. (2015). Analisis Job Performance Pegawai Honorer Administrasi dengan Kompetensi dan Job Characteristics dalam Mendukung Universitas Pendidikan Indonesia Mencapai Leading and Outstanding. Fokus Ekonomi, 10(2), 120137.

Masharyono, Sumiyati, \& Toyib. (2016). Physical Work Environment Effect on Employee Productivity of Textile Industry. Advances in Economics, Business and Management Research, 15, 630-632.

Mathis, R. L., \& Jackson, J. H. (2010). Human Resource Management (13th ed.). United States of America: Cengage Learning.

Mehta, M., Kurbetti, A., \& Dhankhar, R. (2014). Review Paper - Study on Employee Retention and Commitment. International Journal of Advance Research in Computer Science and Management Studies, 2(2), 154-164.

Mejia, L. R., \& Balkin, D. B. (2012). Management: People, Performance and Change. New Jersey: Pearson.

Moeheriono. (2012). Pengukuran Kinerja Berbasis Komputer. Jakarta: Raja Grafindo Persada.

Mohlala, J., Goldman, G. a., \& Goosen, X. (2012). Employee retention within the Information Technology Division of a South African Bank. SA Journal of Human Resource Management, 10(2), 1-12. http://doi.org/10.4102/sajhrm.v10i2.438

Mondy, R. W., \& Martocchio, J. J. (2016). Human Resource Management (14th ed.). United States of America: Pearson.

Msengeti, D. M., \& Obwogi, J. (2015). Effects of Pay and Work Environment on Employee Retention: A Study of Hotel Industry in Mombasa. International Journal of Scientific and Research Publications, 5(4), $1-10$.

Nankervis, A., Rowley, C., \& Salleh, N. M. (2016). Asia Pacific Human Resource Management and Organisational Effectiveness. USA: Chandos.

Nkomo, M. W., \& Thwala, W. D. (2016). Mentoring on Retention of Employees in the Construction Sector: A Literature Review. In Creative Construction Conference (pp. 305-310).

Notoatmodjo. (2010). Metodologi Penelitian
Kesehatan. Jakarta: Rineka Cipta.

Omotayo, O. A., \& Paul, O. (2014). and Job Satisfaction in the Nigerian Banking Industry. Journal of Management Policies and Practices June, 2(2), 63-83.

Rahmawati, P., Sumiyati, \& Masharyono. (2016). Leader Member Exchange dan Kepribadian untuk Meningkatkan Employee Voice Kopontren DT. Strategic Journal, 11, 3844.

Rasool, S., Ayub Kiyani, A., Junaid Aslam, M., Umair Akram, M., \& Ali Rajput, A. (2012). Impact of Organizational Culture on Employee's Career Salience: An Empirical Study of Banking Sector in Islamabad, Pakistan. International Journal of Business and Social Science, 3(7).

Regina. (2015). A Strategic Employee Retention Model Based on Employee Perception. European Journal of Business Management, $\quad 1(5), \quad$ 25-35. http://doi.org/10.1017/CBO9781107415324 .004

Robbins, S. P., \& Coulter, M. (2016). Management (13th ed.). United States of America: Pearson.

Rowley, C., \& Jackson, K. (2012). Manajemen Sumber Daya Manusia Key Concepts (Indonesian). Jakarta: PT RajaGrafindo Persada.

Salman, A., \& Ahmad, N. (2014). Factors Affecting on Employees Retention in Banking Sector: An Investigation from Karachi. European Journal of Business and Management, 6(37), 169-179.

Satpal, \& Dhillon, M. (2016). Retaining Employees in Indian it Sector. International Journal of Science Technology and Management, 5(3), 163-168.

Schultz, D. P., \& Schultz, S. E. (2010). Psychology and Work Today (10th ed.). USA: Routledge.

Sedamaryanti. (2011). Manajemen Sumber Daya Manusia, Reformasi Birokrasi dan Manajemen Pegawai Negeri Sipil. Bandung: PT Rafika Aditama.

Senen, S. H., \& Solihat, S. (2008). Pengaruh Motivasi Kerja dan Kemampuan Kerja Karyawan terhadap Produktivitas Kerja Karyawan pada PT. Safilindo Permata. Jurnal Strategic, 7(14), 1-15.

Senen, S. H., Sumiyati, \& Masharyono. (2016). The Effect of Skill Variety, Task Identity, 
Task Significance, Autonomy and Feedback on Job Performance. Advances in Economics, Business and Management Research, 15, 585-588.

Shakeel, N. (2015). Factors Influencing Employee Retention: An Integrated Perspective. Journal of Resources Development and Management, 6, 32-50.

Shields, J. (2014). Managing Employee Performance and Reward Concepts, Practices, Strategies. Igarss 2014. United States of America: Cambridge. http://doi.org/10.1007/s13398-014-0173-7.2

Shukla, S. (2014). Employee Retention Policies of Public and Private Sector Banks in India: a Comparative Study. A Journal of Management, 7(2), 87-100.

Sinha, C. (2012). Factors Affecting Employee Retention: A Comparative Analysis of two Organizations from Heavy Engineering Industry. European Journal of Business and Management, 4(3), 145-163.

Sumiyati, Masharyono, Pratama, K. F., \& Purnama, R. (2016). The Effect of Social Work Environment on Employee Productivity in Manufacturing Company in Indonesia. Advances in Economics, Business and Management Research, 15, 574-575.

Sutermeister, R. A. (1976). People and productivity (3th ed.). Michigan: McGrawHill.

Terera, S. R. (2014). The Impact of Rewards on Job Satisfaction and Employee Retention. Mediterranean Journal of Social Sciences, $5(1)$, $481-488$ http://doi.org/10.5901/mjss.2014.v5n1p481

Thakur, A. (2014). A Study on Factors Affecting Employee Retention in Retail Sector. International Journal of Multidisciplinary Consortium, 1(1), 37-54.

Thomas, J. (2015). Study on Causes and Effects of Employee Turnover in Construction Industry. International Journal of Science and Research, 4(5), 3041-3044.

Torrington, D., Hall, L., Taylor, S., \& Atkinson, C. (2014). Human Resource Management (9th ed.). London: Pearson. http://doi.org/10.1177/03091325890130010 5

Tulus, M. A. (2011). Manajemen Sumber Daya Manusia. Jakarta: Gramedia Pustaka Utama.
Umamaheswari, S., \& Krishnan, J. (2015). Retention Factors and Their Relative Significance in Ceramic Manufacturing Industries in India. Asian Social Science, 11(13), 260-268. http://doi.org/10.5539/ass.v11n13p260

Wadhana, D., Tarmedi, E., \& Sumiyati. (2016). Upaya Meningkatkan Kinerja dengan Cara Memberikan Motivasi Kerja dan Menumbuhkan Komitmen Organisasional Pegawai Dinas Perhubungan Provinsi Jawa Barat, 1(2), 91-96.

Widyanata, R., \& Senen, S. H. (2016). Pengaruh Lingkungan dan Kemampuan Kerja terhadap Kinerja Karyawan PT. Ronadamar Sejahtera Cabang Bandung. Journal of Business Management Education, 1(2), 4755.

Wilkinson, A., Redman, T., \& Dundon, T. (2017). Contemporary Human Resource Management. United Kingdom: Pearson. 